УДК 397.4

\title{
СРАВНИТЕЛЬНОЕ ИЗУЧЕНИЕ ПРОБЛЕМ РАЗВИТИЯ КУЛЬТУРЫ КЫРГЫЗОВ-КОЧЕВНИКОВ С КУЛЬТУРОЙ АЛТАЙЦЕВ
}

\author{
Ж. Ж. Жакыпбеков
}

Киргизский национальный университет имени Жусупа Баласагына, Бишкек, Кьргызстан

e-mail:ZZhakypbekov@mail.ru

\section{DOI: 10.14258/ssi(2019)4-08}

Изучение истоков кочевой цивилизации, основанное на анализе этнической ментальности и исторических процессов, очень актуально в наши дни. Центральноазиатские ученые сегодня по-разному трактуют духовные начала древних культур кочевников. Некоторые кыргызоведы, опираясь на кыргызскую санжыру, считают, что 3000-3500 лет тому назад в Центральной Азии образовалось Угуз-Уйгурское государство, расположенное на реке Самара, оно стало называться Самаркенти. Государство Угуз во время правления Отор-хана протянулось на западе до Аму-Дарьи и Каспия, а на востоке до Алтайских гор. Казахские философы на основе «Дао Алтая» выдвигают гипотезу, согласно который «золотая земля» (Алтай) породила древнюю цивилизацию - праалтайцев, просветивших территорию Алтаиду, или Гиперборею, а затем все древние цивилизации: Шумер, Египет, Вавилон, Индию, Китай и др.

В работе делается попытка анализа основных моментов сложения и дальнейшего развития духовной культуры кыргызов-кочевников. Все приведенные сюжеты формирования культуры кыргызов-кочевников подтверждены историческими фактами. Проблема исследовалась путем сравнительного анализа культуры кыргызов-кочевников с историей культуры алтайцев.

Ключевые слова: Алтай, алтайцыь, номады, кочевая цивилизация, культура кочевников, проблемы этногенеза кыргызского народа, теория циивилизаций, фагинун, сибирская история, культура алтайцев. 


\title{
A COMPARATIVE STUDY \\ OF THE DEVELOPMENT PROBLEMS \\ OF KYRGYZ-NOMADS' CULTURE WITH ALTAI \\ PEOPLE'S CULTURE
}

\author{
Zh. Zhakypbekov \\ Kyrgyz National University named after Jusup Balasagyn, Bishkek, Kazakhstan \\ e-mail:ZZhakypbekov@mail.ru
}

Nowadays the study of the origins of nomadic civilization, based on an analysis of ethnic mentality and historical process is very relevant. Scientists of Central Asia interpret the spiritual principles of the ancient nomadic cultures in different ways. Some Kyrgyz experts who rely on the Kyrgyz ancestors consider that 3000-3500 years ago Uguz-Uygur state was formed in the Central Asia located on the Samara River became known as Samarkanti. During the reign of Otar Khan the state Uguz stretched to the fmu Darya. In the west and the Caspian Sea, to the Altay Mountains in the east. Kazakh philosophers, based on the «Tao of Altay» put forward a hypothesis according to which «the golden land» gave rise to an ancient civilization - pro-Altaians, enlightened the territory of Altaida or Hyperforea, and then all ancient civilization: Sumer, Egypt, Babylon, India, Cina and so on.

An attempt to analyze the main moments of formation and further development of the spiritual culture of Kyrgyz-nomads is made in the presented report. Au given plots cited in the report are summarized on the basis it a study of historical facts on issues of merger and formation of the culture of Kyrgyz-nomads. The speaker studied this problem through a comparative analysis with the history of Altai people's culture.

Keywords: Altay, Altay people, nomads, nomadic civilization, nomad culture, ethnogenesis problem of Kyrgyz people, civilization theory, Siberian history culture of Altay people.

Изучение истоков кочевой цивилизации и национальных культур, основанное на анализе этнической ментальности и исторических процессов, очень актуально в наши дни. Для центральноазиатских традиционных обществ в древности обитаемые ими пространства были привычными. Поэтому отношение оседлых людей к кочевникам было двойственным. Еще с середины V в. до н.э. греческий историк Геродот в своей «Истории» отмечал идеализируемые моменты из жизни кочевников-скифов (Хазанов, 2000). Со II тысячелетия до н.э. сложилась скотоводческо-земледельческая экономика производящего типа. Подвижные, инициативные скотоводческие племена образовали обширные, могущественные политические объединения. В этот период в некоторых местах Азии впервые появились кочевники. Библия и другие источники содержат сведения о политической и социокультурной истории кочевников древности. Но с научной точки зрения никаких прямых этнокультурных и этнографических системных сведений они не дают. 
Как отмечает академик В.М. Массон, два обстоятельства возвращают историческую науку к истокам общественного прогресса: новые археологические открытия и поиск общих закономерностей в истории общества, как наиболее сложной формы движения материи (Массон, 1989).

Одним из важных рубежей социально-экономического и культурного прогресса является эпоха первых цивилизаций, закономерным образом связанная с первыми государственными образованиями и обществами.

Введение понятия «цивилизация» - достижение европейской науки и литературы XVIII в. Тогда это понятие означало воспитанность и вежливость, включало в себя этические нормы поведения. В 20-30-х гг. XIX в. термин «цивилизация» применяется как понятие к большим эпохам, к целым народам, как универсальное обозначение всего, что создано человеком. В последующие века становилось ясно, что цивилизация сформировалась лишь на определенном этапе развития человечества как качественный рубеж на эволюционном пути, реконструированном в общих чертах еще мыслителями античной эпохи. В этой связи можно смело утверждать, что первые попытки научного изучения жизни кочевников (гуннов, монголов, кыргызов и т.д.) охватывают период античности. Это было описание социополитической организации кочевников: отсутствие земледелия, перекочевки со скотом в зависимости от наличия корма и воды, отсутствие постоянных маршрутов передвижения скота - вот стандартные рассуждения греческих, римских, китайских и других авторов периода средневековья.

В этом контексте можно рассматривать в обобщающей форме социально-экономическое и этнокультурное развитие народов, входящих в алтайскую семью народов, в том числе тюркоязычных этносов.

В наши дни проблемы научных направлений (в частности, исторической науки), условия возникновения новых теорий и парадигм постоянно находятся в центре внимания ученых. Современное развитие гуманитарных наук предполагает комплексный подход, с использованием многих сведений по истории, социологии, философии, культурологии и т.д. Поэтому ранее «незыблемые» концепции по мере накопления конкретных фактов и выводов оказываются в кризисе. О такой закономерной трансформации американский ученый Т. Кун еще в 60 -е гг. XX в. в своей удивительной книге «Структура научных революций» писал: «часто новая парадигма возникает, по крайней мере в зародыше, до того, как кризис зашел слишком далеко или был явно осознан» (Кун, 1975: 117).

Разрабатывая проблему возникновения новых парадигм о роли носителей алтайской языковой семьи в мировой цивилизации, профессор Т. Кененсариев справедливо отмечает, что в настоящее время бурно развивается специальное направление гуманитарной науки - «алтаистика, которая в совокупности с историческими научными достижениями выдвигает все более свежие концепции» (Кененсариев, 2017: 185). Алтайские народы и родственный им ряд этнонимов, имеющие трехтысячелетную историю, составляют большую группу этносов. Они, начиная с эпохи кочевых держав, стояли у истоков всех крупных историко-политических перемен, стали первооткрывателями в перемещении культур и этносов во всех изменениях политической карты Евразии. 
Современные свежие концепции «алтаистики» - истории народов, имеющих общие алтайские историко-культурные и этногенетические корни, в советско-кыргызской историографии возникли не на пустом месте. Так, например, первый кыргызский историк Б. Солтоноев в своей книге «Кыргыз тарыхы» (Бишкек, 2003) несколько раз упомянул о том, что «кыргызы сложились из финских, монгольских, гуннских племен, которые в древности переселились из Средней Азии на Алтай и Орол» (Урал. Ж.Ж.). Они обитали на землях возле реки Енисей, дальше между Урянхайско-Саянскими и Алтайскими горами (Солтоноев, 2003). Следует отметить, что Б. Солтоноев при создании своего труда целенаправленно и широко использовал труды Ошанина, Клапрота, В.В. Бартольда, а также сведения персоязычных и русскоязычных авторов.

Для нас представляет большой интерес также повествование Б. Солтоноева о роли и места бүбү и бакшы в общественной жизни кыргызов. Опираясь на работу персидского автора Гардизи «Зайналь акбар» (работа написана в 1050-1051 гг. по заказу Газневидского султана), он описывает интересные сюжеты из жизни бүбү и бакшы. Вот что мы читаем у Б. Солтоноева по этому поводу: «среди кыргызов (имеются в виду енисейско-алтайские. - Ж.Ж.) живут фагинуны. Они в течение года в определенные дни устраивают религиозные представления (пир) в сопровождении комузистов и кыякистов. Когда музыкальное сопровождение доводится до психологического пика, фагинун в состоянии транса теряет сознание и падает ничком. В таком состоянии он предсказывает, какие природные катаклизмы будут в будущем, урожайный ли год, или засуха в течение этого года». Анализируя такие моменты, Б. Солтоноев прямо указывает, что без сопровождения кыргызских комузистов и кыякистов бакшы или бүбү не может войти в такое психологически напряженное состояние. То есть без комузистов и кыякистов он не может ничего предсказать (Солтоноев, 2003: 28-29). Как видим, Б. Солтоноев, описывая действие фагинуна в момент камлания, нигде не пишет и не упоминает слово «шаман». Вместе с тем их действия он приравнивает к «бүбү» и «бакшы» в здоровом смысле этого слова. Остается добавить, что Б. Солтоноев (1878-1937) много лет ездил по районам, где жили кыргызы, и собрал богатый фактический материал для своей книги «Кызыл кыргыз тарыхы» («История красных кыргызов»). В ней автор на основе собранных им сведений и письменных источников изложил различные вопросы истории кыргызов с древнейших времен до начала XX в.

В период формирования и развития советской исторической науки (20-80-е гг. XX вв.) основные проблемы древней и средневековой истории Кыргызстана учеными исследованы достаточно полно. Среди многочисленных научных работ, имеющих непосредственное отношение к истокам происхождения и формирования этнической культуры кыргызов, выделяется научный труд, где собраны статьи досоветских, советских и кыргызских ученых, который издан в Бишкеке в 1996 г. (Караев, Жусупов, 1996). В данном сборнике опубликованы интересные материалы по древней и средневековой истории кыргызов: сведения, сохранившиеся в древнекитайских письменах, орхоноенисейских памятниках, арабских и персидских письменных источниках, а также отрывки из исторических исследований и научно-популярные очерки кыргызских и русских ученых XIX-XX вв. 
Так, например, профессор И.Б. Молдобаев в сборнике статье «Происхождение этнической культуры кыргызов (III в. до н.э. - XV в. н.э.)» на основе изучения этнографических, фольклорных, археологических, а также научных работ П.Н. Рычкова, В.Н. Татищева, В.В. Бартольда, Н.А. Аристова, С.М. Абрамзона, В.Я. Бутанаева и других раскрывает истоки происхождения и этнической культуры кыргызов. Автор вводит в научный аппарат этнографический и фольклорный материал, собранный лично у коренных народов Южной Сибири и Алтая.

Известный этнограф С.М. Абрамзон, изучая проблемы этнической истории кыргызской народности в 50-60-е гг. XX в., издал в 1971 г. капитальную монографию «Киргизы и их этногенетические и историко-культурные связи». В этой работе автор, отмечая параллели в названиях племен в составе кыргызского и алтайского народов (их свыше 15 племен), писал: «прежней родиной киргизов называется Алтай» (Абрамзон, 1971: 51). С.М. Абрамзон непосредственно связывает эту проблему с вопросом о территории, в пределах которой происходило формирование некоторых этнических компонентов.

Эти выводы С.М. Абрамзона в 90-е гг. ХХ в. были признаны кыргызскими историками. В частности И.Б. Молдобаев в вышеупомянутой статье, продолжая изучение этнической общности кыргызов с тувинцами, хакасами и шорцами, резюмировал: «выявленные одинаковые названия родов и племен, схожие черты хозяйства, общественного строя, материальной и духовной культуры, языка, фольклора кыргызов и народов Саяно-Алтая свидетельствуют об имевшейся этнической и культурной общности между ними. По-прежнему наиболее трудно разрешимым вопросом остается датировка этнокультурных связей кыргызов с народами Саяно-Алтая» (Караев, Жусупов, 1996). Подытоживая свои мысли по данному вопросу, И.Б. Молдобаев приходит к выводу, что синхронность сообщений и легенд о кыргызах и народах Саяно-Алтая указывает не только на существование тесных этнокультурных связей между ними, но и на непременную причастность их к древнекыргызскому этносу.

В суверенный период Кыргызстана (с 31 августа 1991 г. по настоящее время) сравнительные исследования проблем формирования и дальнейшего развития культуры кыргызов-кочевников с культурой народов Южной Сибири продолжались. В городах Бишкек, Чолпон Ата 20-22 июля 2017 г. прошел Международный форум «Алтайская цивилизация и родственные народы алтайской языковой семьи». В ходе работы этого форума профессор Б.М. Төрөгелдиева, анализируя современный этап изучения мировоззрения населения Центральной Азии, справедливо отмечает, что «в формировании этнического самосознания и культуры кыргызов еще с периода VII-X вв. большую роль играли кросскультурные связи с метаэтническими сообществами Алтая» (Төрөгелдиева, 2017: 288). При этом Б.М. Төрөгелдиева считает, что в этническом сознании кочевников героико-эпический идеал занимает основное место в мировоззрении кочевых народов разных эпох. В этом вопросе взгляды Б.М. Төрөгелдиевой и А.М. Мокеева совпадают. Профессор А.М. Мокеев в своей фундаментальной монографии «Кыргызы на Алтае и на Тянь-Шане» доказывает, что «именно эти алтайские кыргызы в эпоху распада Монгольской империи в силу ряда ... причин стали мигрировать в Семиречье... и в конце XV - начале XVI в. 
полностью овладели территорией Тянь-Шаня. Фольклорные выражение этих процессов нашло широкое отражение в эпосе „Манас“. Во всех известных вариантах эпоса рождение эпического героя происходит на Алтае, откуда он после достижения зрелого возраста переселяется со своим народом на Ала-Тоо. В этом наиболее ярко проявилась глубинная историческая память кыркызского народа, для которого имя его героического героя и название прародины неразделимы» (Мокеев, 2010: 246).

Из всего вышеизложенного вытекает, что начало развития и взаимодействия культур родственных народов алтайской языковой семьи происходило на территории Южной Сибири. Устные предания и легенды о кыргызах имеются почти у всех народов Южной Сибири. Кыргызы оставили этнокультурные связи от Енисея и северо-западной Монголии до Теңир-Тоо, в Ферганской долине и на Памире, в горах Ала-Тоо и в Восточном Туркестане. Такой широкий диапазон их этнокультурных контактов в значительной степени подкрепляется и топонимами, упомянутыми в эпосе «Манас».

В настоящее время казахский философ С. Куттыкадам в своей книге «Дао Алтая. Исток человеческой цивилизации» прослеживает процессы, происходившие при переселении народов в разных частях света, выходит на «нулевую точку» — это палеолитическая обитель: Изначальное знание (Куттыкадам, 2015).

Как справедливо отмечает С. Ключников, понять логику истории, на которую действует множество разнообразных факторов, очень непросто (Ключников, 2015). В этом плане С. Куттыкадам берет себе в помощь идеи двух мыслителей прошлого. Это автор «Заката Европы» немецкий историк О. Шпенглер с его мифологическими представлениями о развитии государства и Рене Генон, французский эзотерик, основатель философии традиционализма, чьи идеи об участии сакрального начала в истории и жизни набирают сегодня все большую популярность. Эти идеи сводятся к слудующему.

О. Шпенглер утверждает, что понятие о культурно-исторических типах, равноположенных друг другу, исключает идею превосходства более поздних цивилизаций над ранними и «отсталыми», что постоянно имеет место в американских и западных исторических теориях. С. Куттыкадам, вводящий понятие протоалтайцев как первых людей высокого разума, подчеркивает, что он не оспаривает признанную теорию, согласно которой первые люди на планете появились в Африке.

О. Шпенглер смотрел на развитие различных культур как на естественный процесс планетарного характера. Его концепция притягивает специалистов своим подлинным, естественным демократизмом в подходе к истории, не формально, а реально признающим эволюционное равенство.

Рене Генон, выбравший ислам в качестве своего главного духовного ориентира, первым на Западе заявивший об изначальной традиции, ввел в интеллектуально-культурный оборот понятие «центр мира», столь важное при исследвании сакрального Алтая.

В этом контексте философия С. Куттыкадама отличается от подхода О. Шпенглера отсутствием заданности исторического процесса. Книга С. Куттыкадама «Дао Алтая...» интересна также многообразием рассмотренных тем и проблем. Автор 
считает, что с учетом абсолютно разных географических, пространственных, климатических и исторических особенностей континент Евразия можно делить не на две части света - Азию и Европу, а на три: Азию, Европу и Гиперборею (Алтаиду).

Кыргызовед-философ Б. Жумабаев в книге «Кыргыз таануу», (2018), опираясь на санжыру манасчы Балыкооза, пишет, что 3000-3500 лет тому назад в Центральной Азии образовалось Угуз-Уйгурское государство. Впоследствии это государство, рассположенно на реке Самара, стало называтся Самаркенти. Государство Угуз во время правления Отор-хана протянулось на западе до Аму-Дарьи и Каспия, а на Востоке - до Алтайских гор (Жумабаев, 2018: 18).

Сегодня ученые пытаются ответить на вопрос: почему люди из первобытного животного состояния перешли к осознанной жизнедеятельности, т.е. откуда пошло человеческое сознание.

\section{БИБЛИОГРАФИЧЕССКИЙ СПИСОК}

Абрамзон С.М. Киргизы и их этногенетические и историко-культурные связи. Л.: Наука, 1971.

Жумабаев Б. Кыргыз таануу. Бишкек: Улуу тоолор, 2018.

Караев О., Жусупов К. (Ред.). Кыргызы: источники, история, этнография. Бишкек, 1996.

Кененсариев Т. Новые парадигмы о роли носителей алтайской языковой семьи в мировой цивилизации. В кн.: Алтайская цивилизация и родственные народы алтайской языковой семьи. Бишкек: Турар, 2017.

Ключников С. Дао философа из Казахстана. Мысль, 2015, №. 10, 14-21.

Кун Т. Структура научных революций. М: Прогресс, 1975.

Куттыкадам С. Дао Алтая. Исток человеческой цивилизации. М: Беловодье, 2015.

Массон В.М. Первые цивилизации. Л.: Наука, 1989.

Мокоеев А.М. Кыргызы на Алтае и на Тянь-Шане. Бишкек, 2010.

Солтоноев Б. Кыргыз тарыхы. Бишкек: Архи, 2003.

Төрөгелдиева Б. М. Алтайская цивилизация: мировоззренческие истоки кыргызской культуры. В кн.: Алтайская цивилизация и родственные народы алтайской языковой семьи. Бишкек: Турар, 2017.

Хазанов А.М. Кочевники и внешний мир. Алматы: Дайк-Пресс, 2000.

\section{REFERENCES}

Abramzon, S.M. (1971). Kirgizy i ikh etnogeneticheskie i istoriko-kulturnye svyazi [Kyrgyz and their ethnogenetic and historical and cultural ties]. Leningrad: Nauka.

Zhumabaev, B. (2018). Kyrgyz taanuu [Recognition of Kyrgyz]. Bishkek: Uluu toolor, 2018. 
Karaev, O., Zhusupov, K. (1996) (Eds.). Kyrgyzy: istochniki, istoriyia, etnografiya [Kyrgyz: sources, history, ethnography]. Bishkek.

Kenensariev, T. (2017). Novye paradigmy o roli nositelej altaiskoj yazykovoj sem»i $\mathrm{v}$ mirovoj civilizacii [New paradigms about the role of Altay language family holders in global civilization]. In: Altay civilization and kin peoples of the Altaian language family. Bishkek: Turar, 2017.

Klyuchnikov, S. (2015). Dao filosofa iz Kazakhstana. Mysl', no 10, 14-21.

Kun, T. (1975). Struktura nauchnyh revoliucij [The Structure of Scientific Revolutions]. M: Progress.

Kuttykadam, S. (2015). Dao Altaya. Istok chelovecheskoj civilizacii [Dao of the Altai. The dawn of human civilization]. M: Belovode.

Masson, V.M. (1989). Pervye civilizacii [The first civilizations]. L.: Nauka.

Mokoeev, A.M. (2010). Kyrgyzy na Altae i na Tyan-Shane [Kyrgyz in the Altai and the Tien Shan]. Bishkek, 2010.

Soltonoev, B. (2003). Kyrgyz tarykhy [Kyrgyz history]. Bishkek: Arkhi.

Teregeldieva, B.M. (2017). Altaiskaya civilizaciya: mirovozzrencheskie istoki kyrgyzskoj kultury [Altay civilization: worldview roots of Kyrgyz culture]. In: Altay civilization and kin peoples of the Altaian language family. Bishkek: Turar, 2017.

Khazanov, A.M. (2000). Kochevniki i vneshnij mir [Nomadic peoples and external world]. Almaty: Daik-Press. 